\title{
Removal Research of Modified Zeolite Phosphorus in Wastewater
}

\author{
Jinlong Zuo \\ Research Center on Life Science and Environmental \\ Science, Department of Environmental Engineering, \\ Harbin University of Commerce \\ Engineering Research Center of Natural Anticancer \\ Drugs, Ministry of Education \\ Harbin, China \\ Email: mdjzjl@163.com
}

\section{Hui Li}

Research Center on Life Science and Environmental Science

Engineering Research Center of Natural Anticancer

Drugs, Ministry of Education

Harbin, China

Email: huihui232@126.com

\author{
Junxia Wang \\ Research Center on Life Science and Environmental \\ Science \\ Engineering Research Center of Natural Anticancer \\ Drugs, Ministry of Education \\ Harbin, China \\ Email: hhswwjx@126.com
}

\author{
Xue Li \\ Research Center on Life Science and Environmental \\ Science \\ Engineering Research Center of Natural Anticancer \\ Drugs, Ministry of Education \\ Harbin, China \\ Email: 584276505@qq.com
}

Ruifeng E

Research Center on Life Science and Environmental Science

Engineering Research Center of Natural Anticancer Drugs, Ministry of Education

Harbin, China

Email: 450536651@qq.com

\begin{abstract}
Recently years many large lakes are eutrophic or in serious state of eutrophication. And most eutrophic water from phosphorus control action is the amount of input, so how to effectively reduce the phosphorus content of sewage has become noticeable within the field of environmental protection issues. In the present study natural zeolite as material and finding that the original zeolite adsorption effect only is $8 \%-18 \%$. Due to the removal effect, choose modified zeolite, through to the acid and alkali salt for respectively, then insure that using $20 \% \mathrm{MgCl} 2$ best of static test examines the $\mathbf{p H}$, temperature, adsorption time , the effects of the removal rate could reach $70 \%-85 \%$. The last time, dosing quantity for the orthogonal experiment research, determine the optimum condition of the adsorption is at $25{ }^{\circ} \mathrm{C}, 160 \mathrm{~min}, 5 \mathrm{~g}$ respectively, and the removal efficiency can reach $82 \%$.
\end{abstract}

Keywords-Zeolite ; Adsorbent influence; Phosphorus removal adsorbent; Modification; Secondary sewage discharge standards;

\section{INTRODUCTION}

With the rapid development of industry and agriculture, high concentrations of phosphorus- containing wastewater and domestic sewage is not treated directly discharged into water bodies, resulting in excessive levels of nitrogen and phosphorus in the water, causing eutrophication. Zeolite is zeolite minerals in general, are widely distributed in the Earth's crust. Zeolite is a shelf-like aluminum silicate, a high water content of the alkali and alkaline earth metals are a prerequisite for the formation of zeolite.

Adsorption properties of zeolite: Zeolite has a large internal surface area, up to $500 \sim 1000 \mathrm{~m}^{2} / \mathrm{g}$, so the zeolite has a large diffusion capacity, but also has good adsorption properties. In exchange properties of the zeolite: the spatial structure of the zeolite base unit 4 is an oxygen atom and a silicon atom or a silicon atom piled into alumina tetrahedral.

Choose some place of natural zeolite with phosphorus additives together with the activation treatment of wastewater, the modified zeolite can effectively remove the sewage phosphide, but based on poly phosphide phosphorus wastewater treatment effect is not ideal. Phosphorus optimum conditions are: zeolite particle size 0.5-1.6mm, water $\mathrm{pH}=4-12$, a phosphorus concentration of $30 \mathrm{mg} / \mathrm{L}$, filtration speed $3 \mathrm{~m} / \mathrm{h}$. Based on the experience of phosphorus modified zeolite materials and foreign scholars, this paper intends to use alkali treatment, alt treatment, high temperature roasting method of combining natural zeolite modified. 


\section{MATERIAL AND METHODS}

\section{A. Materials}

\section{1) Anatural zeolite}

Zeolite is a family of frame-like structure of hydrous aluminum silicate minerals. It mainly contains $\mathrm{Na}$ and $\mathrm{Ca}$, and a small number of $\mathrm{Sr}, \mathrm{Ba}, \mathrm{K}, \mathrm{Mg}$ and other metal ions. Since silicon different oxygen tetrahedron connection, he formation of many voids and pores in the zeolite structure, his unique structure and chemical properties of the zeolite crystal has excellent physical and chemical properties, uch as ion exchange, adsorption, thermal stability resistance, cid resistance.

\section{2) Test water}

Phosphorus content is at $2-4 \mathrm{mg} / \mathrm{L}$, nitrogen and COD content is at $15-20 \mathrm{mg} / \mathrm{L}$ and $100 \mathrm{mg} / \mathrm{L}$.

\section{B. Methods}

\section{Measurement items and equipment}

Experimental determination the project are mainly phosphorus concentration, $\mathrm{pH}$. Phosphorus concentrations of molybdenum, antimony anti-spectrophotometric instrument with 722 spectrophotometer, $\mathrm{pH}$ was measured using a $\mathrm{pH}$ meter.

\section{1) A basic principle}

Under acidic conditions, the positive reaction with Ammonium phosphate, potassium tartrate antimony oxide, generating phosphomolybdic heteropoly acid. Stannous reducing agent is restored, turn blue complex, commonly referred to as phosphorus molybdenum blue. The color of the $700 \mathrm{~nm}$ wavelength has a strong absorption.

\section{2) Determination of step}

a) The calibration curve

Take six $50 \mathrm{ml}$ stoppered colorimetric tube were added phosphate standard solution $0,0.50,1.00,3.00,5.00,7.00$ and $10.0 \mathrm{ml}$, diluted with water to the mark.

Color : add $5 \mathrm{ml}$ molybdate solution, mix, stannous chloride solution was added to $0.25 \mathrm{ml}$ colorimetric tube ,and mix.

Measurement: room temperature $\left(20^{\circ} \mathrm{C}\right)$ after $20 \mathrm{~min}$ placed at a wavelength of $700 \mathrm{~nm}$, optical drive $10 \mathrm{~mm}$ cuvette with distilled water as a reference, measure the absorbance. From the measured absorbance of the sample by subtracting the absorbance of the reference water, the corrected absorbance plotted phosphorus content $(\mu \mathrm{g})$ of the corrected absorbance of the calibration curve.

\section{b) Determination of water samples}

Take the right amount of water samples (make phosphorus does not exceed $30 \mu \mathrm{g}$, usually raw water $1 \mathrm{ml}$, water $5 \mathrm{ml}$ ) in colorimetric tube, diluted with water to the mark. The following steps according to the standard curve for color measurement. Subtracting the absorbance of the blank test, and a phosphorus content isolated from the calibration curve.

\section{RESULT}

\section{A. Natural zeolite adsorption}

Weigh $5 \mathrm{~g}$ original zeolite into250ml Erlenmeyer flask, were added to $50 \mathrm{ml}$ phosphorus in water samples, $25^{\circ} \mathrm{C}$ water bath oscillator oscillating $0.5,1,1.5,2,2,5$ hours, sampling $5 \mathrm{ml}$ in colorimetric tube, fixed volume to $50 \mathrm{ml}$. Molybdate solution was added $5 \mathrm{~mL}$ mix, add a solution of stannous chloride $0.25 \mathrm{ml}$ stick sufficiently uniform, color 20 minutes. Distilled water to make a reference, $700 \mathrm{~nm}$ wavelength spectrophotometer absorbance was measured.

According to the experiment, we can conclude that the effect of the removal of contaminants in water samples with phosphorus relatively poor natural zeolite and phosphorus removal rate is only around $11 \%$, so our natural zeolites can be used to remove phosphorus pollutants in water samples. The reason is that the original zeolite pores is no valid immobilized phosphate, making the zeolite pores in the phosphate free access, while a negative for some time after adsorption is due to the structure of the zeolite phosphorus out of the water samples free of phosphorus content increased. It can be seen, for the modification of the original zeolite shall have its inner surface and pores carrier absorption of phosphorus.

\section{B. Select modifier}

After soaking acid salt brine soak best analysis were obtained. After verification, soaked with $20 \% \mathrm{MgCl}_{2}$ best, take $5 \mathrm{~g}$ original zeolite, the supernatant was poured into $250 \mathrm{~mL}$ draw $25 \mathrm{~mL}$ volumetric flask, dilute to volume, measured twice each parallel solution, the absorbance was measured.

Modified zeolite obtained optimum conditions for the test :

Zeolite into concentration $1 \mathrm{~mol} / \mathrm{L} \mathrm{NaOH}$ solution in soaking $35^{\circ} \mathrm{C}$ temperature oscillation, removed after soaking, cleaning and zeolite, washed with deionized water and dried. The treated zeolite is placed above the concentration of $20 \% \mathrm{MgCl}_{2}$ solution soak, $35^{\circ} \mathrm{C}$ temperature oscillation, after soaking $2 \mathrm{~d}$ removed, washed and dried. The zeolite after $\mathrm{NaOH}$ treatment and $\mathrm{MgCl}_{2}$ placed in a muffle furnace, and calcined at $500{ }^{\circ} \mathrm{C}$ for $2 \mathrm{~h}$, after removing the natural dry.

\section{Univariate tests of modified zeolite}

1) Effect of soaking time on the adsorption of phosphorus

Take 6 volumes of $250 \mathrm{ml}$ Erlenmeyer flask, $50 \mathrm{~mL}$ each bottle has been loaded with good phosphorus in water samples. Were added to each bottle modified zeolite. Placed in a water bath shaker at room temperature $\left(25^{\circ} \mathrm{C}\right)$ oscillations, took out a flask at regular intervals, sampling $5 \mathrm{ml}$ in colorimetric tube, the volume to $50 \mathrm{ml}$. Adding $5 \mathrm{~mL}$ molybdate solution mix, 3 plus $0.25 \mathrm{~mL}$ stannous solution thoroughly mixed, color 20 minutes. Distilled water to make a reference, $700 \mathrm{~nm}$ wavelength spectrophotometer absorbance was measured. According to the standard curve to calculate the amount of 
phosphorus, calculated removal and adsorption capacity for removal and adsorption capacity vs time, reaction time relationship with the phosphorus concentration in water is shown in Fig .1.

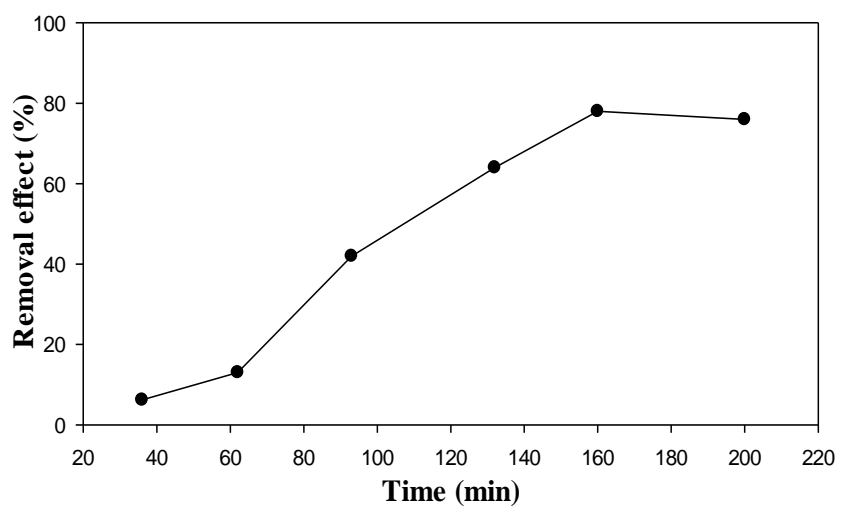

Figure 1. The time and removal rate curve

Obtained from the above experiment, the phosphoruscontaining wastewater treatment, time to $160 \mathrm{~min}$ degradation results were better than the maximum degradation rate of $72.33 \%$.

2) The influence of temperature on the removal of the modified zeolite

Weigh $5 \mathrm{~g}$ sample into $250 \mathrm{ml}$ conical flask, add $50 \mathrm{ml}$ water sample phosphorus, water bath oscillator, respectively, the temperature-controlled oscillator at $10,15,20,25,30{ }^{\circ} \mathrm{C} 3$ hours, the test methods above, for the removal and adsorption the amount of change over time chart shown in Fig .2

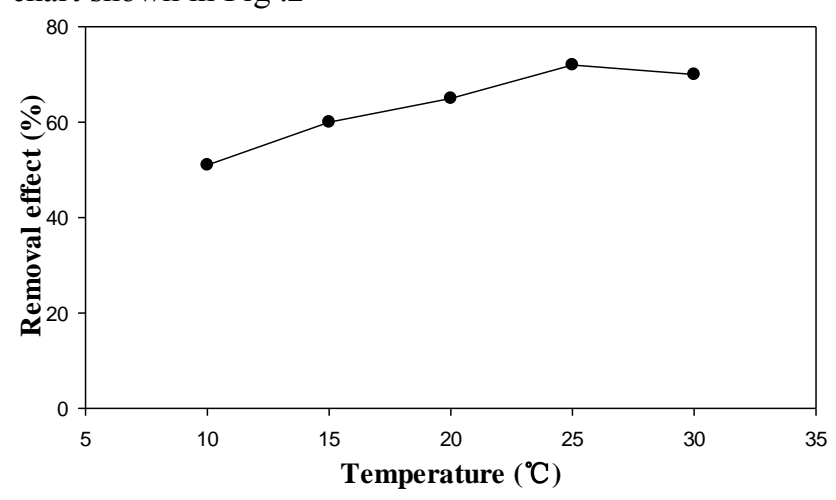

Figure 2. The temperature and removal rate curve

3) The impact of the dosage of modified zeolite and phosphorus removal

Take different amounts of modified zeolite material handling 1,2,3,4,5 $\mathrm{g}$ of phosphorus in water samples $50 \mathrm{~mL}$, measured adsorption $3 \mathrm{~h}$. Test methods, test methods above, removal and adsorption capacity for change with time chart, the test results are shown in Fig .3:

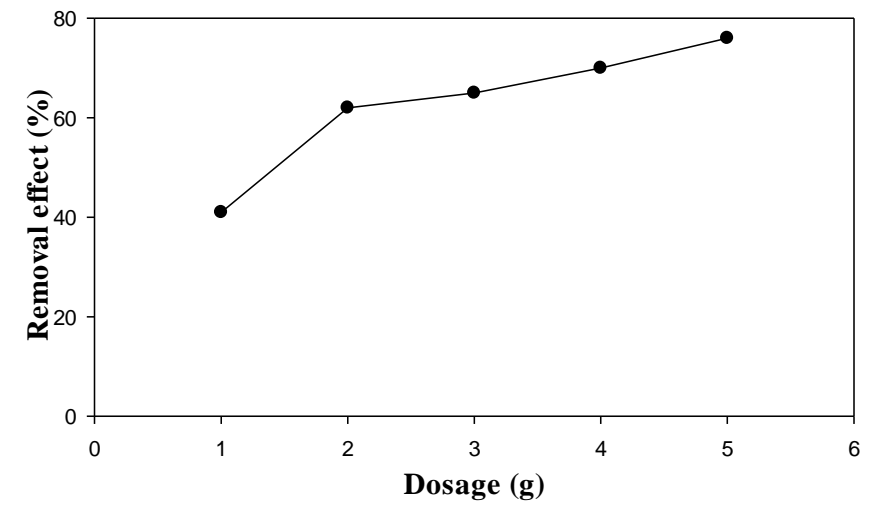

Figure 3. Dosage and removal rate curve

It is shown in the chart that with the increase in dosage is getting better adsorption, absorption is best when adding $5 \mathrm{~g}, 5 \mathrm{~g}$ so experiments were taken as the standard.

4) Orthogonal modified zeolite and phosphorus removal

a) Orthogonal take three factors in selecting

Univariate analysis using orthogonal experiment and method of combining research and phosphorus modified zeolite to various factors. Orthogonal mainly consider the following factors:

1. Effects of soaking time, the impact of different zeolite adsorption time of phosphorus removal efficiency. The trial investigated $120 \mathrm{~min}, 150 \mathrm{~min}, 180 \mathrm{~min}$, affecting three times zeolite removal of phosphorus.

2. Temperature. This test uses $20{ }^{\circ} \mathrm{C}, 25{ }^{\circ} \mathrm{C}, 30{ }^{\circ} \mathrm{C}$ for the three levels of orthogonal experiment.

3. How much influence the dosage and zeolite catalytic water samples, the greater the dosage under normal circumstances, the higher the efficiency of the zeolite and phosphorus, but the dosage is too big, too expensive, not conducive phosphorus. This test uses $1 \mathrm{~g}, 3 \mathrm{~g}, 5 \mathrm{~g}$ of three levels of orthogonal experiment. Orthogonal factor levels are shown in Table 1

TABLE I. THE ORTHOGONAL EXPERIMENT FACTOR LEVEL

\begin{tabular}{|c|c|c|c|}
\hline Factor & Level 1 & Level 2 & Level 3 \\
\hline Time(min) & 120 & 160 & 180 \\
\hline Temperature $\left({ }^{\circ} \mathrm{C}\right)$ & 20 & 25 & 30 \\
\hline Dosage $(\mathrm{g})$ & 1 & 3 & 5 \\
\hline
\end{tabular}

b) Orthogonal test results and anal 
TABLE II. THE ORTHOGONAL EXPERIMENT RESULT TABLE

\begin{tabular}{|l|l|l|l|l|}
\hline Items & Time & Temperature & Dosage & Removal/\% \\
\hline 1 & 1 & 1 & 1 & 61.6 \\
2 & 1 & 2 & 2 & 62.2 \\
3 & 1 & 3 & 3 & 65.3 \\
4 & 2 & 1 & 2 & 71.5 \\
5 & 2 & 2 & 3 & 77.6 \\
6 & 2 & 3 & 1 & 68.2 \\
7 & 3 & 1 & 3 & 74.3 \\
8 & 3 & 2 & 1 & 67.4 \\
9 & 3 & 3 & 2 & 66.6 \\
K1 & 1.688 & 2.655 & 1.871 & \\
K2 & 2.264 & 2.098 & 2.109 & \\
K3 & 2.203 & 2.012 & 2.155 & \\
Poor R & 0.376 & 0.077 & 0.224 & \\
Excellent & $\mathrm{A}_{1}$ & $\mathrm{~B}_{2}$ & $\mathrm{C}_{3}$ & \\
level & & & & \\
\hline
\end{tabular}

Analysis can be seen by the poor:

1. Size of each factor as follows: Time $>$ dosage $>$ temperature. The test results showed that the zeolite while phosphorus removal efficiency is relatively high, the need to further explore the mechanism of phosphorus removal.

2. The minimum temperature adsorption of zeolite.

3. From the test results, the time was $150 \mathrm{~min}$, temperature $25^{\circ} \mathrm{C}$, the dosage is best to remove the effect of $5 \mathrm{~g}$.

\section{CONCLUSION}

1.Use the following steps when natural zeolite modified phosphorus best: natural clinoptilolite washed with deionized water, $\mathrm{NaOH}$ solution and drying $1 \mathrm{~mol} / \mathrm{L}$ of $35{ }^{\circ} \mathrm{C}$ soaking $1 \mathrm{~h}, 20 \% \mathrm{MgCl}_{2}: 35{ }^{\circ} \mathrm{C}$ under dynamic solution soak $2 \mathrm{~d}$, in a muffle furnace at $500{ }^{\circ} \mathrm{C}$ calcined at 2h, the $105{ }^{\circ} \mathrm{C}$ drying.

2. After the modified zeolite, the skeleton structure has not changed, but the silica to alumina ratio is changed, the porosity increases, and the load surface of the zeolite, magnesium hydroxide, so that the active adsorption sites increase, thereby increasing the adsorption of zeolite $\mathrm{P}$ performance. Natural zeolites have almost no phosphorus removal capabilities, and the ability of the modified zeolite adsorption greatly enhanced.

3 . The adsorption capacity of modified zeolite is contact time, temperature, $\mathrm{pH}$ value of the solution, the dosage and other factors.

4. When the modified zeolite univariate tests found that the biggest factor affecting the time, and is not dosage, temperature and $\mathrm{pH}$, and therefore the selected time, dosage, temperature do three factors and three levels orthogonal trials.

5. The orthogonal test showed: $160 \mathrm{~min}, 25^{\circ} \mathrm{C}$ and $5 \mathrm{~g}$ the best results can be achieved by $82 \%$.

\section{ACKNOWLEDGMENT}

This research is financially supported by Natural Science Foundation of Heilongjiang Province of China (NO. E201355).

\section{REFERENCES}

[1] Miettinen I T, Vartiainen T, Martikainen P J. Contamination of drinking water [J].Nature, 1996,381:654-655.

[2] Sathasivan A, Ohgaki S, Yamamoto K, et al. Role of inorganic phosphorus in controlling regrowth in water distribution system $[\mathrm{J}]$ Sci.Tech.,1997,35(8):37-44.

[3] Zhang Jihua Chemical precipitation of phosphate wastewater treatment [J]. Industrial Water Treatment, 2000,20 (5) :43-44.

[4] Ding Wenming, Huang Xia Progress wastewater phosphorus adsorption of $[\mathrm{J}]$ environmental pollution control technology and equipment, 2002,3(10): 23-27.

[5] Dudong Yun. Phosphorus wastewater treatment [J]. Chemica engineer, 1997,61 (4) :34-39.

[6] Zhang Zijie drainage works [M] Beijing: China Building Industry Press, 2006:320-322. Wang JL, Wen Xianghua modern environmental biotechnology [M] Beijing: Tsinghua University Press, 2001:257-259.

[7] Wang Shasha study [J]. Environmental phosphorus pollution hazards and phosphorus commonly used method of economic research and education, 2006:34.

[8] Noureddine Hamdi, Ezzeddine Srasra .Removal of phosphate ions from aqueous solution using Tunisian clays minerals and synthetic zeolite[J]. Journal of Environmental sciences .2011.21:12-20

[9] S.A.Wassay. Adsorption of fluoride, phosphate, and arsenate ions on anthanum-impregnated silica gel[J]. Wat. Env. Res.1996, 68(3):295-300.

[10] Y. Seida. Removal of phosphate by layered double hydroxides containing iron.Wat. Res., 2002, 36:13061312compound.Ecological Engineering, 1999, 12:339-351. 